\title{
The inulin hydrolysis by recombinant exo-inulinases: determination the optimum temperatures and activation energies
}

\author{
Justyna Miłek ${ }^{1}$ (D) \\ Received: 8 February 2021 / Accepted: 19 September 2021 / Published online: 9 October 2021 \\ (c) The Author(s) 2021
}

\begin{abstract}
The advantages of recombinant enzymes over native include the control in a production environment, product purity and also high yield. The paper presents the determination the optimum temperatures and the activation energies for various origin recombinant exo-inulinases, among others from Aspergillus niger, A. awamori, Kluyveromyces marxianus and K. cicerisporus. The parameters were estimated based on the literature of the activity curves versus temperature for hydrolysis of inulin. It was assumed that both the hydrolysis reaction process and the deactivation process of recombinant exo-inulinase were first-order reactions by the enzyme concentration. A mathematical model describing the effect of temperature on recombinant exo-inulinase activity was used. Based on the comparison analysis, values of the activation energies $E_{\text {a }}$ were in the range from $32.01 \pm 7.80$ to $43.83 \pm 4.87 \mathrm{~kJ} \mathrm{~mol}^{-1}$, the deactivation energies $E_{\mathrm{d}}$ were in the range from $83.93 \pm 4.82$ to $352.44 \pm 14.26 \mathrm{~kJ} \mathrm{~mol}^{-1}$ and the optimum temperature $T_{\text {opt }}$ were obtained in the range from $318.91 \pm 1.19$ to $328.76 \pm 0.25 \mathrm{~K}$.
\end{abstract}

Keywords Optimum temperature $\cdot$ Recombinant exo-inulinase $\cdot$ Activation energy $\cdot$ Deactivation energy

\section{Introduction}

Enzymes are characterized, among others by the optimum temperature. When its exceeded, there is thermal denaturation of enzyme and a rapid decrease in enzyme activity. The knowledge of the optimum temperature $T_{\text {opt }}$ and the activation energy $E_{\mathrm{a}}$ and deactivation energy $E_{\mathrm{d}}$ of the enzyme enables the optimization of the bioprocess and the reduction of its costs at the same time. The $T_{\text {opt }}$ value is mostly determined experimentally. On the other hand, the value of the activation energy $E_{\mathrm{a}}$ and $E_{\mathrm{d}}$ can be determined from the curves of the dependence of the logarithm of the reaction rate $(\ln v)$ on the reciprocal of temperature $(1 / T)$, the socalled Arrhenius dependence [1]. However, the determined values of $E_{\mathrm{a}}$ and $E_{\mathrm{d}}$ by application of the traditional method is burdened with an error $[2,3]$.

Inulinases (2,1- $\beta$-D-fructan fructanohydrolase) catalyze the hydrolysis of inulin to obtain fructose with a yield of

Justyna Miłek

jmilek@utp.edu.pl

1 Department of Chemical and Biochemical Engineering, Faculty of Chemical Technology and Engineering, Bydgoszcz University of Science and Technology, Seminaryjna 3, 85-326 Bydgoszcz, Poland about $90-95 \%$. Inulin consists of linear chains of $2,1-\beta$ -D-fructofuranose molecules terminated with a glucose residue at the reducing end. Inulin is a reserve carbohydrate $(0.5-22 \%)$ in plant tubers like Jerusalem artichoke, chicory, garlic and onion, leek, rye, barley, dandelion, burdock, banana [4-7]. Inulinases can be divided into endoinulinases (EC 3.2.1.153) and exo-inulinases (EC 3.2.1.80). Exo-inulinases remove terminal fructose residues from the non-reducing end of inulin, and endo-inulinases act on the internal bonds of the inulin molecule and can be used to produce fructooligosaccharides [8-10]. Inulinases occur in plants, fungi, yeasts and bacteria. Strains belonging to Aspergillus sp. and Kluyveromyces sp. are the most common and preferred for the production of inulinase. Inulinases obtained from them are characterized by high activity and high thermostability [5].

The optimum value of $\mathrm{pH}$ for inulinase $A$. niger is the same for both exo- and endo-inulinase and equals to 5.0. However, the optimal temperatures of most exo-inulinase are above $50{ }^{\circ} \mathrm{C}[7]$.

Inulinases can be used for industrial purposes in the production of high-fructose syrups, bioethanol production, production of fructose and glucose oligosaccharides (therapeutic products as prebiotics), unicellular oils and production of 
a unicellular protein in the production of citric acid, butanediol, alcohols and lactic acid (Table 1) [5, 11-15].

The advantages of recombinant enzymes over native include the control in a production environment, product purity and also high yield. Efficient production of inulinases on an industrial scale can significantly reduce the costs of biocatalyst, reduce energy consumption and improve the efficiency of fructose production [8].

Some exo-inulinase genes have been expressed in bacteria Escherichia coli and yeast Saccharomyces cerevisiae, Yarrowia lipolytica, Pichia pastoris and fungi Penicillium canescens [14-20]. The goal of scientists is to obtain the recombinant inulinases that are more thermostable at different $\mathrm{pH}$ than the native strains.

There have been many publications in the literature on recombinant exo-inulinases from fungi A. niger [14, 17, 18, 20], A. awamori [15] and from yeast $K$. cicerisporus [16] and K. marxianus [19]. However, processes involving this recombinant exo-inulinase for industrial purposes cannot be designed and optimized without knowing the kinetic parameters of the process and thus the effect of temperature on activity recombinant exo-inulinase [21]. Hydrolysis with recombinant exo-inulinases is usually carried out at temperatures higher than $45^{\circ} \mathrm{C}$ then, a significant inactivation of the enzyme may occur. Therefore, it is necessary to determine the optimum temperature $T_{\text {opt }}$, activation energy $E_{\mathrm{a}}$ and activation energy of the deactivation process $E_{\mathrm{d}}$ for recombinant exo-inulinases. The method of determining the parameters based on experimental data on the effect of temperature on the activity recombinant of exo-inulinases has been presented [14-20].

\section{The effect of temperature on recombinant exo-inulinase activity}

The value of the activation energy $E_{\mathrm{a}}$ and the deactivation energy $E_{\mathrm{d}}$ of inulinase can be determined using: the enzymatic reaction rate curve $v$, as the relationship between $\ln v$ versus temperature inverse $T$ or the curve of inulinase activity $a$, as dependence between $\ln a$ relation to the inverse of temperature $T$. Activation energies or deactivation energies in hydrolysis reactions involving various types of inulinase [21-23] were determined. In this work, the basic equation (mathematical model) of the presented method is the equation describing the change in the dimensionless activity of the enzyme $a$ depending on the temperature $T$ as follows

$a=\frac{\exp \left(\frac{\left(T_{\mathrm{opt}}-T\right) E_{\mathrm{d}} \beta}{R T T_{\mathrm{opt}}(\exp \beta-1)}\right)\left(1-\exp \left(-\beta \exp \left(\frac{\left(T-T_{\mathrm{opt}}\right) E_{\mathrm{d}}}{R T T_{\mathrm{opt}}}\right)\right)\right)}{1-\exp (-\beta)}$,

where $T_{\text {opt }}$ is the temperature at which recombinant exoinulinase shows maximum activity $(\mathrm{K}), E_{\mathrm{d}}$ is the activation energy of the deactivation process $\left(\mathrm{J} \mathrm{mol}^{-1}\right), R$ is gas constant $\left(8.314 \mathrm{~J} \mathrm{~mol}^{-1} \mathrm{~K}^{-1}\right), T$ is temperature $(\mathrm{K})$ and dimensionless parameter $\beta$ determines the relationship

$\beta=k_{\mathrm{d} 0} t_{\mathrm{a}} \exp \left(-\frac{E_{\mathrm{d}}}{R T_{\mathrm{opt}}}\right)$,

where $k_{\mathrm{d} 0}$ is a pre-exponential factor the kinetic constant of the deactivation process of recombinant exo-inulinase $\left(\mathrm{min}^{-1}\right)$ and $t_{\mathrm{a}}$ is an inulin hydrolysis time of recombinant exo-inulinases ( $\mathrm{min}$ ).

Knowing the value of the activation energy of the deactivation reaction $E_{d}$ and the parameter $\beta$, the activation energy $E_{\mathrm{a}}$ is determined by equation

$E_{\mathrm{a}}=E_{\mathrm{d}}-\frac{E_{\mathrm{d}} \beta}{\exp \beta-1}$,

Equations from equal (1) to equal (3) were used to determine the kinetic parameters of p-nitrophenyl palmitate hydrolysis by lipases [24], starch hydrolysis by $\alpha$-amylase from porcine pancreas [25] and inulin hydrolysis by exo-inulinases A. niger [26] or by endo-inulinase Aspergillus niger [27].

Based on Eq. (1), the kinetic parameters $E_{\mathrm{d}}$ and $T_{\mathrm{opt}}$ were determined by a nonlinear regression according to the Levenberg-Marquardt procedure [24-32], determining the minimum sum of squared errors defined by Eq. (4)

$\operatorname{SSE}\left(E_{\mathrm{a}}, \beta, T_{\text {opt }}\right)=\sum_{i=0}^{n} \frac{1}{\left(a_{\text {exp }}\right)_{\mathrm{i}}^{2}}\left(\left(a_{\text {exp }}\right)_{\mathrm{i}}-a_{\text {cal }}\left(E_{\mathrm{a}}, \beta, T_{\mathrm{i}}, T_{\text {opt }}\right)\right)^{2}$,

where $\left(a_{\exp }\right)_{\mathrm{i}}$ - recombinant exo-inulinase of various origins activity determined experimentally, $a_{\mathrm{cal}}\left(E_{\mathrm{a}}, \beta, T_{\mathrm{i}}, T_{\mathrm{opt}}\right)$ - recombinant exo-inulinase of various origins activity calculated from Eq. (1).
Table 1 Products from origin inulin hydrolysed by recombinant exo-inulinase

\begin{tabular}{llll}
\hline Substrate & Source inulinase & Products & References \\
\hline Asparagus inulin & K. marxianus YS-1 & High fructose syrup & {$[5]$} \\
Jerusalem artichoke & A. niger & Lactic acid & {$[11]$} \\
Jerusalem artichoke & K. cicerisporus & Ethanol & {$[12]$} \\
Jerusalem artichoke & K. marxianus ATCC 8554 & Ethanol & {$[13]$} \\
Inulin & Recombinant A. niger & Fructose syrup & {$[14]$} \\
\hline
\end{tabular}




\section{Results and discussion}

Experimental literature data [14-20] were analyzed for exoinulinases from various yeast and bacteria. Table 2 shows the conditions for measuring insulin activity, such as $\mathrm{pH}$ and a buffer type, time measurement. In most cases, the analyzed inulinase activities were determined by using the NelsonSomogyi [15, 20] method and the DNS method [14-17], using dinitrosalicylic acid. The initial inulin concentration measured was in the range of $1 \%-5 \%$.

Used strains by Chen et al. [14] has been obtained from own the Laboratory of Biology and Pharmaceutical Engineering, Wuhan Polytechnic University in China. A.niger exo-inulinase gene was codon-optimized and co-expressed with the protein in Pichia cells. In the hydrolysis of inulin by recombinant exo-inulinase $A$. niger, a fructose syrup product with a content of fructose of $95 \%$ was obtained.

Volkov et al. [15] analyzed the recombinant exo-inulinase obtained from exo-inulinase gene A. awamori strain into $P$. canescens A3. Used strains has been obtained from the Laboratory of Enzyme Biotechnology in Bach Institute of Biochemistry, Russian Academy of Sciences.

Gene encoding an exoinulinase was cloned from $\mathrm{K}$. cicerisporus CBS4857 and expressed in P. pastoris X-33 [16]. Arjomand et al. [18] applied A. niger 5012 to the cloning process to $E$. coli $\mathrm{DH} 5$. The cloning process creates a mutant called $\triangle 6 \mathrm{SL}$. The recombinant exo-inulinase A. niger 5012 $\triangle 6 \mathrm{SL}$ was lowering the activation energy of the catalysis and effective improving the catalytic performance. The purified by Zhang et al. [19] recombinant exo-inulinase $K$. marxianus CBS 6556 to $P$. pastoris showed an activity which is over 12-fold higher than those of other inulinases described previously. Liu et al. [20] used $K$. marxianus KM-0 strain (collection number 2E001023) and Y. lipolytica Po1h strain (collection number 2E0189) from Marine Microorganisms Culture Collection of China (MCCC).

\section{The effect of temperature on the recombinant exo-inulinases activity}

Based on experimental data on the change in the activity of recombinant exo-inulinases [14-20], and Eq. (1); the value of deactivation energies $E_{\mathrm{d}}, \beta$ parameters and temperatures optimal $T_{\text {opt }}$ were determined from Eq. (1). Figures 1-7 show experimental data on recombinant exoinulinases activity, along with activity curves plotted based on Eq. (1) for the values of the specified parameters $E_{\mathrm{d}}, E_{\mathrm{a}}, \beta$ listed in Table 3.

Statistical analysis was used to analyze, interpret and summarize experimental data. Results expressed as mean values with error bars indicating standard deviations, whereas the $95 \%$ confidence band was additionally marked for the obtained curves. Data obtained from results were analyzed by nonlinear regression using Sigma Plot 12.3.

With the values of the activation energy parameter for the deactivation reaction $E_{\mathrm{d}}$ and the parameter $\beta$, the activation energy value was calculated based on Eq. (3).

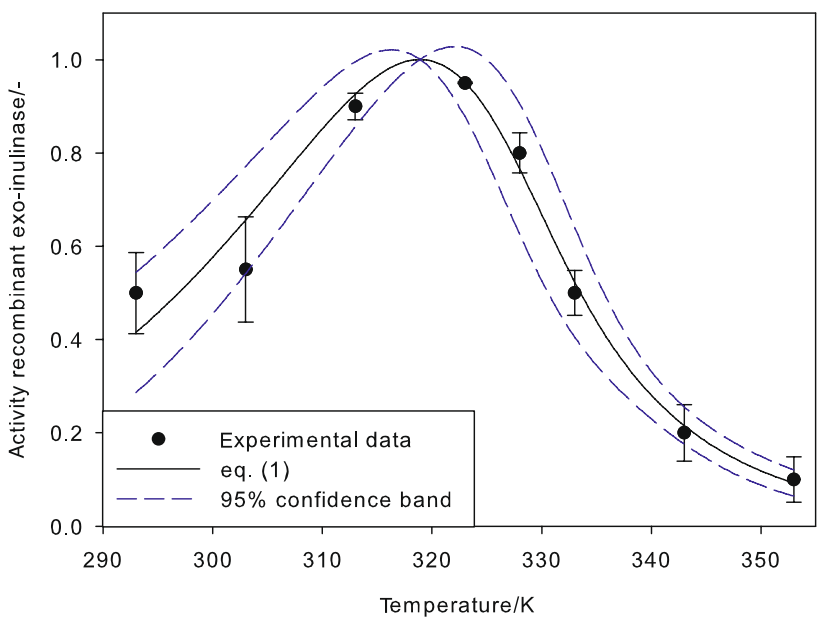

Fig. 1 Activity of recombinant exo-inulinase A. niger CBS 513.8 by measurements Chen et al. [14]
Table 2 Conditions for measuring of recombinant exoinulinases activity

\begin{tabular}{|c|c|c|c|c|}
\hline $\mathrm{pH}$ buffer & $t / \min$ & $\begin{array}{l}\text { Concentration } \\
\text { of inulin/\% }\end{array}$ & Source of inulinase & References \\
\hline 5.5 sodium acetate & 5 & 5 & A. niger CBS 513.8 to P. pastoris & [14] \\
\hline 5.0 sodium acetate & 5 & 1 & A. awamori to $P$. canescens $\mathrm{A} 3$ & {$[15]$} \\
\hline 4.5 sodium acetate & 10 & 2 & K. cicerisporus $\mathrm{CBS} 4857$ to P. pastoris X-33 & [16] \\
\hline 4.5 sodium acetate & 5 & 1 & Recombinant $A$. niger (Megazyme) & {$[17]$} \\
\hline 5.0 sodium acetate & 8 & 1 & $\begin{array}{l}\text { A. niger } 5012 \text { to E. coli DH5 (A. niger } 5012 \\
\triangle 6 \mathrm{SL})\end{array}$ & {$[18]$} \\
\hline 4.6 sodium acetate & 30 & 5 & K. marxianus CBS 6556 to $P$. pastoris & [19] \\
\hline 4.5 phosphate & 10 & 2 & K. marxianus KM-0 to Y. lipolytica Polh & {$[20]$} \\
\hline
\end{tabular}




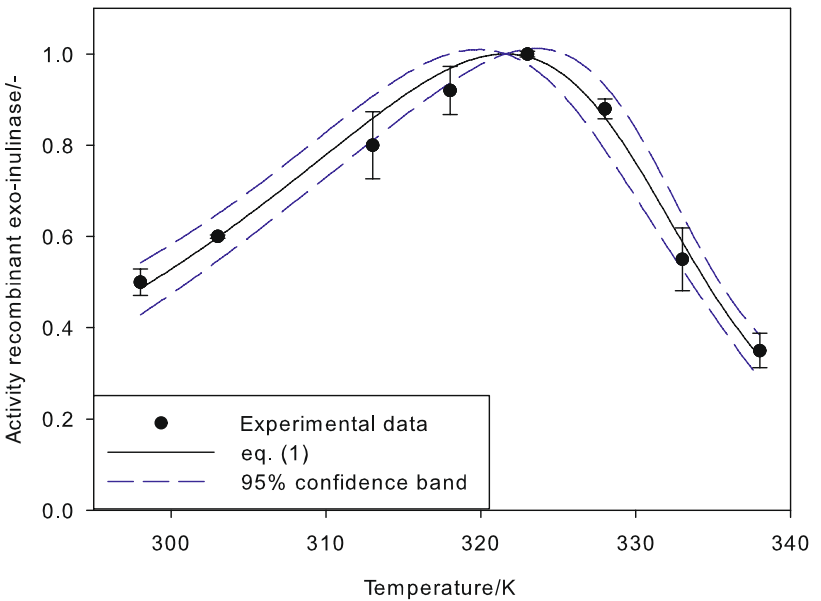

Fig. 2 Activity of recombinant exo-inulinase A. awamori by measurements Volkov et al. [15]

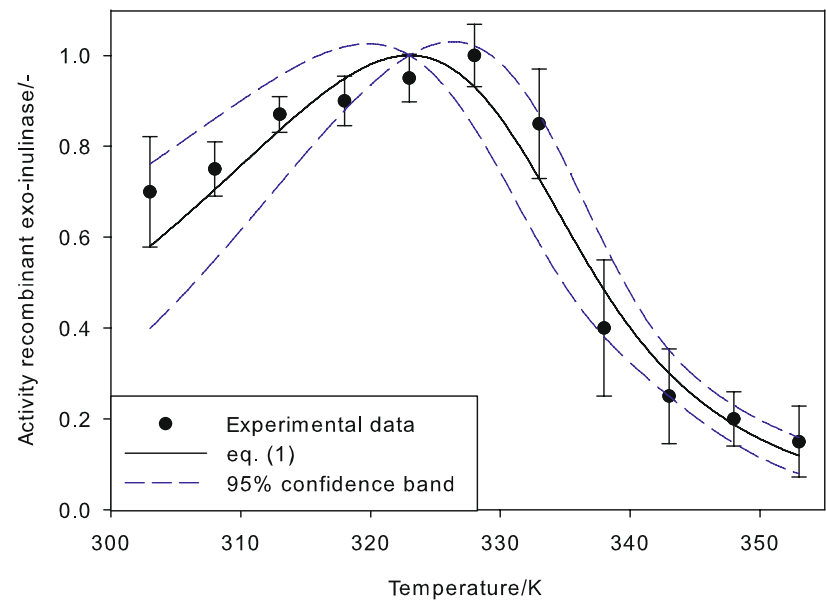

Fig. 3 Activity of recombinant exo-inulinase $K$. cicerisporus CBS4857 by measurements Ma et al. [16]

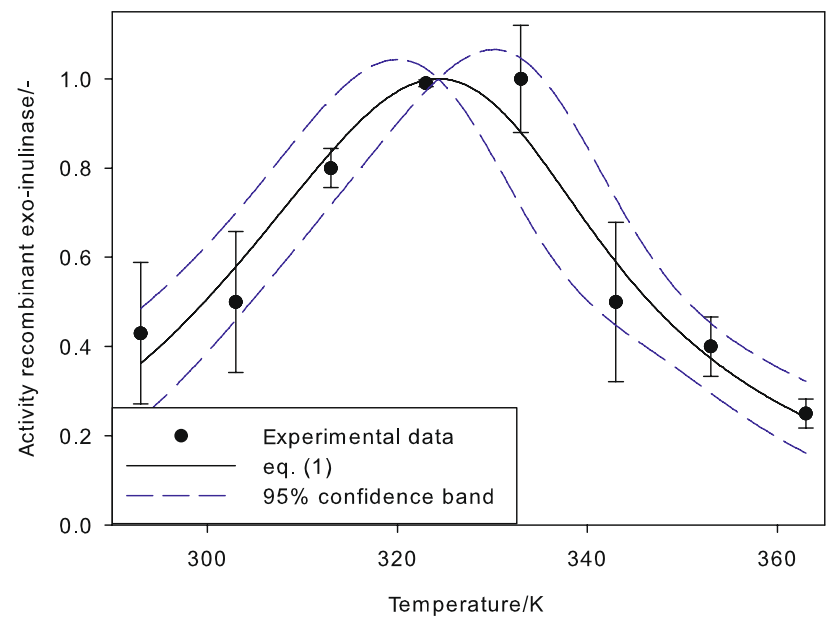

Fig. 4 Activity of recombinant exo-inulinase A. niger by measurements Megazyme [17]

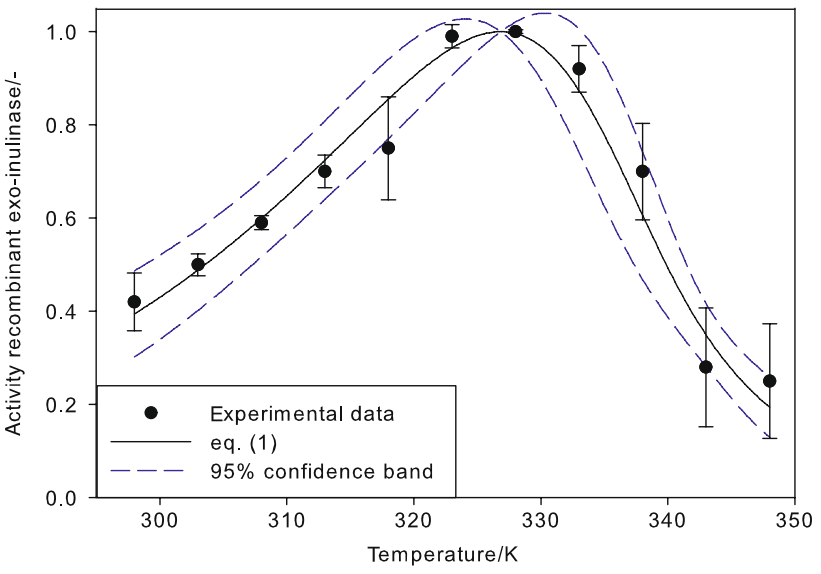

Fig. 5 Activity of recombinant exo-inulinase A. niger $5012 \triangle 6$ SL by measurements Arjomand et al. [18]

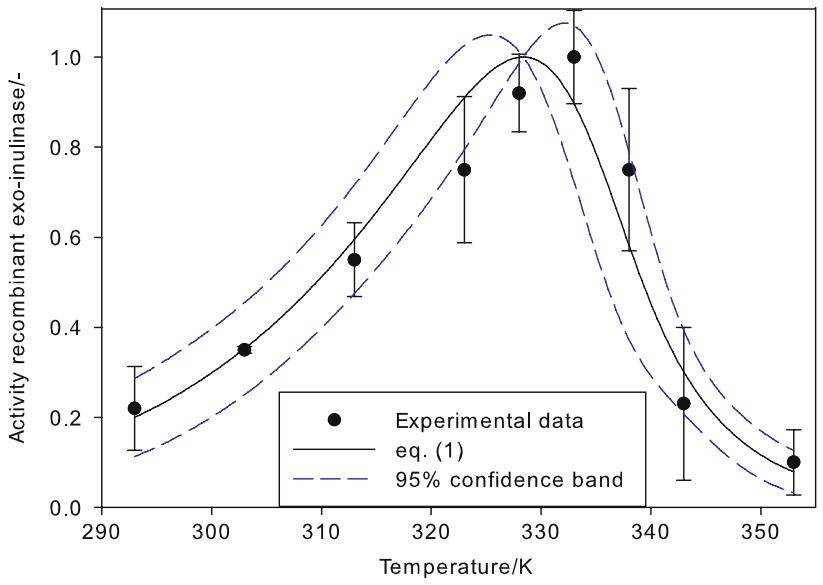

Fig. 6 Activity of recombinant exo-inulinase K. marxianus CBS 6556 by measurements Zhang et al. [19]

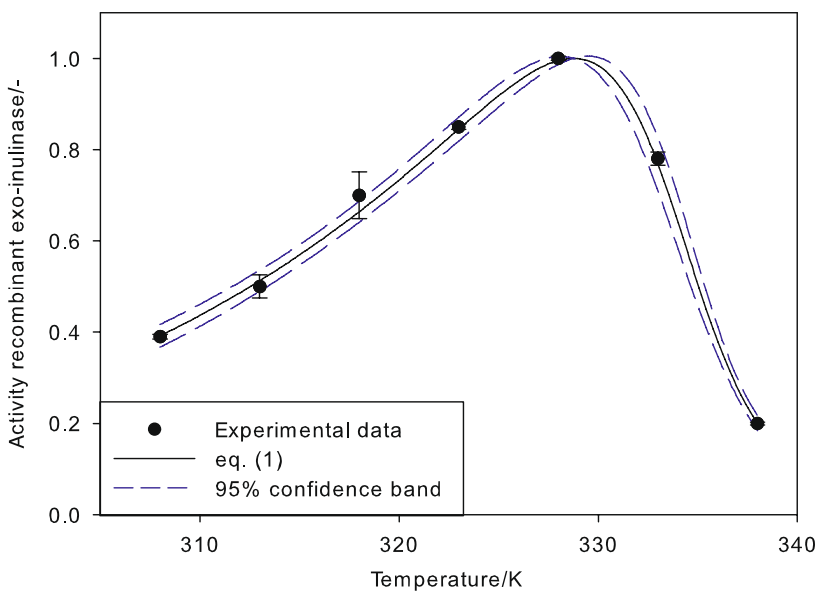

Fig. 7 Activity of recombinant exo-inulinase $K$. marxianus KM-0 by measurements Liu et al. [20] 
Table 3 Values of parameters estimated recombinant exoinulinases from various origin

\begin{tabular}{lllllll}
\hline Fig. & $T_{\text {opt }} / \mathrm{K}$ & $\beta$ & $E_{\mathrm{d}} / \mathrm{kJ} \mathrm{mol}^{-1}$ & $E_{\mathrm{a}} / \mathrm{kJ} \mathrm{mol}^{-1}$ & $E_{\mathrm{d}} / E_{\mathrm{a}}$ & References \\
\hline 1 & $318.91 \pm 1.19$ & $0.66 \pm 0.11$ & $120.87 \pm 6.18$ & $35.53 \pm 7.17$ & 3.40 & {$[14]$} \\
2 & $321.60 \pm 0.76$ & $0.48 \pm 0.09$ & $144.92 \pm 12.15$ & $32.01 \pm 7.80$ & 4.53 & {$[15]$} \\
3 & $323.00 \pm 1.47$ & $0.57 \pm 0.16$ & $126.18 \pm 9.99$ & $32.56 \pm 10.35$ & 3.86 & {$[16]$} \\
4 & $324.32 \pm 2.37$ & $1.09 \pm 0.26$ & $83.93 \pm 4.82$ & $37.59 \pm 9.23$ & 2.23 & {$[17]$} \\
5 & $326.84 \pm 1.15$ & $0.47 \pm 0.14$ & $149.40 \pm 19.30$ & $32.37 \pm 12.08$ & 4.62 & {$[18]$} \\
6 & $328.39 \pm 1.66$ & $0.52 \pm 0.12$ & $176.91 \pm 19.93$ & $42.03 \pm 12.72$ & 4.21 & {$[19]$} \\
7 & $328.76 \pm 0.25$ & $0.26 \pm 0.02$ & $352.44 \pm 14.26$ & $43.83 \pm 4.87$ & 8.01 & {$[20]$}
\end{tabular}

The obtained calculation values $E_{\mathrm{a}}$ results are presented in Table 3.

The obtained parameters for recombinant exo-inulinase were presented in Table 3 , according to the increasing value of the activation energy of the deactivation reaction.

Table 4 presents statistical data obtained while determining the parameters of recombinant exo-inulinases from various origin.

High regression coefficients $R^{2}$ above 0.926 , standard errors of SSE estimation below 0.2113 were obtained; while statistical variability of $E_{\mathrm{d}}$ and $T_{\mathrm{opt}}$ parameters in most of the analyzed cases $p<0.0001$. $F$-Fisher test values were from 31.33 to 1140.12 with a probability value $P$ in most of the analyzed cases is low 0.0003 confirmed that it was appropriated to apply Eq. (1) when determining parameters. Also, Figs. 1-7 present standard deviation errors for experimental points, while the $95 \%$ confidence bonds were marked for the obtained curves.

\section{Optimum temperature $T_{\text {opt }}$}

The estimated average values of the optimum temperatures $T_{\text {opt }}$ for the experimental data [14-20] were found in the range from $318.91 \pm 1.19$ to $328.76 \pm 0.25 \mathrm{~K}$. Table 3 shows that the highest temperature value was obtained for measurements of activity for recombinant exo-inulinase $K$. marxianus KM-0 to Y. lipolytica Po1h [20].

For the A. niger no-recombinant exo-inulinase [26], it was found that they were in the range from $325.25 \pm 0.41$ to $337.35 \pm 0.70 \mathrm{~K}$, and these values are higher than $T_{\mathrm{opt}}$ obtained for recombinant exo-inulinase from A.niger. Norecombinant exo-inulinase can be used to inulin hydrolysis industrial process that take place at higher temperature.

\section{The activation energy $E_{\mathrm{a}}$}

The calculated energy values for activation of $E_{\mathrm{a}}$ were in the range of $32.01 \pm 7.80$ to $43.83 \pm 4.87 \mathrm{~kJ} \mathrm{~mol}^{-1}$ for recombinant exo-inulinases. For the $A$. niger no-recombinant exoinulinase [26], it was found that values $E_{\mathrm{a}}$ are in the range of $25.20 \pm 2.29$ to $60.95 \pm 8.30 \mathrm{~kJ} \mathrm{~mol}^{-1}$. The lowest value of $E_{\mathrm{a}}$ the inulin hydrolysis by recombinant exo-inulinase means that enzyme catalysis is easier than for inulin hydrolysis by no-recombinant exo-inulinase.

\section{The activation energy for enzyme deactivation $E_{\mathrm{d}}$}

The values of activation energies of the deactivation reaction of $E_{\mathrm{d}}$ for recombinant exo-inulinases were obtained in the range from $83.92 \pm 4.82$ to $352.44 \pm 14.26 \mathrm{~kJ} \mathrm{~mol}^{-1}$ (Table 3 ). The highest deactivation energy $E_{d}$ value was obtained for the fungal recombinant exoinulinase Kluyveromyces marxianus, which together with an endo-inulinase gene from A. niger F4 were cloned and expressed in Y. lipolytica Po1h [20]. In this case, not only the recombinant exoinulinase was obtained, but also such an effect of synergistic connection between exo-inulinase and endo-inulinase that
Table 4 The statistical data obtained by determining the parameters of recombinant exoinulinases

\begin{tabular}{|c|c|c|c|c|c|c|c|c|}
\hline \multirow[t]{2}{*}{ Fig. } & \multirow[t]{2}{*}{$R^{2}$} & \multirow[t]{2}{*}{ SSE } & \multicolumn{3}{|l|}{$p$} & \multirow[t]{2}{*}{$F$} & \multirow[t]{2}{*}{$P$} & \multirow[t]{2}{*}{ References } \\
\hline & & & $E_{\mathrm{d}}$ & $\beta$ & $T_{\mathrm{opt}}$ & & & \\
\hline 1 & 0.9783 & 0.1287 & $<0.0001$ & $<0.0001$ & 0.0020 & 112.57 & $<0.0001$ & [14] \\
\hline 2 & 0.9834 & 0.0561 & $<0.0001$ & $<0.0001$ & 0.0029 & 147.91 & $<0.0001$ & [15] \\
\hline 3 & 0.9522 & 0.1570 & $<0.0001$ & $<0.0001$ & 0.0075 & 79.75 & $<0.0001$ & [16] \\
\hline 4 & 0.9261 & 0.1442 & $<0.0001$ & $<0.0001$ & 0.0090 & 31.33 & 0.0015 & [17] \\
\hline 5 & 0.9314 & 0.1404 & $<0.0001$ & $<0.0001$ & 0.0080 & 54.27 & $<0.0001$ & [18] \\
\hline 6 & 0.9310 & 0.2113 & $<0.0001$ & 0.0001 & 0.0053 & 40.50 & 0.0003 & [19] \\
\hline 7 & 0.9973 & 0.0300 & $<0.0001$ & $<0.0001$ & 0.0001 & 1140.12 & $<0.0001$ & [20] \\
\hline
\end{tabular}


the obtained enzyme is characterized by optimal parameters, predisposing it to industrial use.

For the Arjomand et al. [18] measurements the $E_{\mathrm{d}}$ value was obtained $149.40 \pm 19.30 \mathrm{~kJ} \mathrm{~mol}^{-1}$ for recombinant inulinase A. niger $512 \triangle 6 \mathrm{SL}$ and this value is $40 \%$ lower than that the $E_{\mathrm{d}}$ value obtained for no-recombinant exoinulinase from $A$. niger in previous work [26] as equal to $245.62 \pm 26.18 \mathrm{~kJ} \mathrm{~mol}^{-1}$. Mazutti et al. [21] studied directly deactivation of inulinase and have found value $343.9 \mathrm{~kJ} \mathrm{~mol}^{-1}$ for inulinase $K$. marxianus NRRL Y-7571. The activation energy of the deactivation reaction of $E_{\mathrm{d}}$ the commercial exo- and endo-inulinase of $A$. niger for marked $k_{\mathrm{d}}$ Ricca et al. [22] calculated $E_{\mathrm{d}}$ as equal to $313.47 \mathrm{~kJ} \mathrm{~mol}^{-1}$. The $E_{\mathrm{d}}$ values are in the range from $80.86 \pm 3.59 \mathrm{~kJ} \mathrm{~mol}^{-1}$ to $268.66 \pm 24.06$ $\mathrm{kJ} \mathrm{mol}^{-1}$ for the A. niger no-recombinant exo-inulinase [26] and obtained $E_{\mathrm{d}}$ values (Table 3 ) are within the range of values reported to obtained for no-recombinant exo-inulinase from A. niger.

In most of the analyzed cases, recombinant exo-inulinases have lower value of $E_{d}$, so they are less thermally stable than that no-recombinant exo-inulinases from A. niger [26].

Knowing the $E_{\mathrm{d}} / E_{\mathrm{a}}$ relationship for a given recombinant exo-inulinase one can choose the enzyme with the highest thermal stability. The higher the $E_{\mathrm{d}} / E_{\mathrm{a}}$ value of a given recombinant exo-inulinase, the more stable the enzyme is.

\section{Conclusions}

The method of determining following kinetic parameters: the activation energies $E_{\mathrm{a}}$ and the deactivation energies $E_{\mathrm{d}}$ as well as and the optimum temperatures $T_{\mathrm{opt}}$ of inulin hydrolysis reaction by recombinant exo-inulinases from fungi Aspergillus niger and Aspergillus awamori and from yeast Kluyveromyces marxianus and Kluyveromyces cicerisporus; based on curves of changes in recombinant exo-inulinases depending on the temperature of hydrolysis was applied.

For the optimum temperatures $T_{\text {opt }}$, the difference between the obtained values is about $10 \mathrm{~K}$. The differences in the calculated values of activation energy of the reaction $E_{\mathrm{d}}$ is equal to about $270 \mathrm{~kJ} \mathrm{~mol}^{-1}$, the activation energy of the deactivation reaction $E_{\mathrm{a}}$ is equal to about $8 \mathrm{~kJ} \mathrm{~mol}^{-1}$. Advances in genetic modification research and bioprocess technology have improved inulinase activity, optimal $\mathrm{pH}$ and temperature.

The large differences between the energy value $E_{\mathrm{d}}$ for recombinant exo-inulinases result from a different origin of yeast and bacteria strains. Knowledge of presented parameters for recombinant exo-inulinase yeast will allow design, modeling and optimization process of inulin hydrolysis using this enzyme.
Open Access This article is licensed under a Creative Commons Attribution 4.0 International License, which permits use, sharing, adaptation, distribution and reproduction in any medium or format, as long as you give appropriate credit to the original author(s) and the source, provide a link to the Creative Commons licence, and indicate if changes were made. The images or other third party material in this article are included in the article's Creative Commons licence, unless indicated otherwise in a credit line to the material. If material is not included in the article's Creative Commons licence and your intended use is not permitted by statutory regulation or exceeds the permitted use, you will need to obtain permission directly from the copyright holder. To view a copy of this licence, visit http://creativecommons.org/licenses/by/4.0/.

\section{References}

1. Ghaderi F, Nemati M, Siahi-Shadbad MR, Valizadeh H, Monajjemzadeh F. Evaluation of activation energy conformity derived from modelfree non-isothermal predictions and Arrhenius isothermal results. J Therm Anal Calorim. 2017;130:1417-27.

2. Šimon P, Dubaj T, Cibulková Z. Equivalence of the Arrhenius and non-Arrhenian temperature functions in the temperature range of measurement. J Therm Anal Calorim. 2015;120:231-8.

3. Hefczyc B, Siudyga T, Zawadiak J, Mianowski A. Analysis of the thermal decomposition of azo-peroxyesters by Arrheniustype and three-parameter equations. J Therm Anal Calorim. 2011;105:981-6.

4. Espinosa-Andrews H, Rodríguez-Rodríguez R. Water state diagram and thermal properties of fructans powders. J Therm Anal Calorim. 2018;132:197-204.

5. Singh RS, Dhaliwal R, Puri M. Production of high fructose syrup from Asparagus inulin using immobilized exoinulinase from Kluyveromyces marxianus YS-1. J Ind Microbiol Biotechnol. 2007;34:649-55.

6. Chi ZM, Zhang T, Cao TS, Liu XY, Cui W, Zhao CH. Biotechnological potential of inulin for bioprocesses. Bioresour Technol. 2011;102:4295-303.

7. Rawat HK, Soni H, Treichel H, Kango N. Biotechnological potential of microbial inulinases: recent perspective. Crit Rev Food Sci Nutr. 2017;57:3818-29.

8. Singh RS, Chauhan K. Production, purification, characterization and applications of fungal inulinases. Curr Biotechnol. 2018;7:242-60.

9. Chi Z, Chi Z, Zhang T, Liu G, Yue L. Inulinase-expressing microorganisms and applications of inulinases. Appl Microbiol Biotechnol. 2009;82:211-20.

10. Qiu Y, Lei P, Zhang Y, Sha Y, Zhan Y, Xu Z, Li S, Xu H, Ouyang P. Recent advances in bio-basedbased multi-products of agricultural Jerusalem artichoke resources. Biotechnol Biofuels. 2018;11(151):1-15.

11. Ge X, Qian H, Zhang W. Improvement of L-lactic acid production from orange peels in mixed culture system. J Global Biosci. 2014;3(1):354-60.

12. Yuan W, Chang B, Chen L, Bai F. Ethanol production from Jerusalem artichoke by SSF fermentation using Kluyveromyces cicerisporus. J Biotechnol. 2010;150:367-8.

13. Yuan WJ, Zhao XQ, Ge XM, Bai FW. Ethanol fermentation with Kluyveromyces marxianus from Jerusalem artichoke grown in salina and irrigated with a mixture of seawater and freshwater. J Appl Microbiol. 2008;105(6):2076-83.

14. Chen G-J, Yang J-K, Peng X-B, He J-R. High-level secretory expression of Aspergillus exo-inulinase and its use in the preparation of fructose syrup from inulin. J Mol Catal B Enzym. 2016;133:S543-51. 
15. Volkov PV, Sinitsyna OA, Fedorova EA, Rojkova AM, Satrutdinov AD, Zorov IN, Okunev ON, Gusakov AV, Sinitsyn AP. Isolation and properties of recombinant inulinases from Aspergillus sp. Biochemistry. 2012;77:492-501.

16. Ma J-Y, Cao H-L, Tan H-D, Hu X-J, Liu W-J, Du Y-G, Yin H. Cloning, expression, characterization, and mutagenesis of a thermostable exoinulinase from Kluyveromyces cicerisporus. Appl Biochem Biotechnol. 2016;178:144-58.

17. Megazyme, Exo-inulinase Aspergillus niger. (technical information) www.megazyme.com/documents/Booklet/E-EXOIAN DATA.pdf. Accessed from 152021.

18. Arjomand MR, Habibi-Rezaei M, Ahmadian G, Hassanzadeh M, Karkhane AA, Asadifar M, Amanlou M. Deletion of loop fragment adjacent to active site diminishes the stability and activity of exo-inulinase. Int J Biol Macromol. 2016;92:1234-41.

19. Zhang S, Yang F, Wang Q, Hua Y, Zhao ZK. High-level secretory expression and characterization of the recombinant Kluyveromyces marxianus inulinase. Process Biochem. 2012;47:151-5.

20. Liu Y, Zhou S-H, Cheng Y-R, Chi Z, Chi Z-M, Liu G-L. Synergistic effect between the recombinant exo-inulinase and endo-inulinase on inulin hydrolysis. J Mol Catal B Enzym. 2016;128:27-38.

21. Mazutti M, Ceni G, Di Luccio M, Treichel H. Production of inulinase by solid-state fermentation: effect of process parameters on production and preliminary characterization of enzyme preparations. Bioprocess Biosyst Eng. 2007;30:297-304.

22. Ricca E, Calabrŏ V, Curcio S, Iorio G. Optimization of inulin hydrolysis by inulinase accounting for enzyme time- and temperature-dependent deactivation. Biochem Eng J. 2009;48:81-6.

23. Santos AMP, Oliveira MG, Maugeri F. Modelling thermal stability and activity of free and immobilized enzymes as a novel tool for enzyme reactor design. Bioresour Technol. 2007;98:3142-8.

24. Miłek J. Determination of the activation energies and optimum temperature for the hydrolysis of p-nitrophenyl palmitate catalyzed by lipases. Przem Chem. 2021;100:103-4.
25. Miłek J. Determination of activation energies and the optimum temperatures of hydrolysis of starch by $\alpha$-amylase from porcine pancreas. Molecules. 2021;26(4117):1-9.

26. Miłek J. Application of the new method to determine of the kinetic parameters of inulin hydrolysis by exo-inulinase Aspergillus niger. J Therm Anal Calorim. 2021. https://doi.org/10.1007/ s10973-020-10495-3.

27. Miłek J. Determination the optimum temperatures and activation energies of inulin hydrolysis by endo-inulinase Aspergillus niger. Chem Proc Eng. 2020;41:229-36.

28. Maleki A, Haghighi A, Shahrestani MI, Abdelmalek Z. Applying different types of artificial neural network for modeling thermal conductivity of nanofluids containing silica particles. J Therm Anal Calorim. 2021;144(1):1613-22.

29. Miłek J. Thermodynamics and kinetics of thermal deactivation of catalase Aspergillus niger. Pol J Chem Technol. 2020;22(2):67-72.

30. Treichel H, Mazutti MA, Filho FM, Rodrigues MI. Technical viability of the production, partial purification and characterization of inulinase using pretreated agroindustrial residues. Bioprocess Biosyst Eng. 2009;32:425-33.

31. Zhou Z, Li A, Bai R, Sun J. Thermal analysis and gelation property of multifunctional epoxy resins used for pultruded composite ropes. J Therm Anal Calorim. 2014;115:1601-8.

32. Kayran S, Doymaz I. Determination of drying kinetics and physicochemical characterization of apricot pomace in hot-air dryer. $\mathrm{J}$ Therm Anal Calorim. 2017;130:1163-70.

Publisher's Note Springer Nature remains neutral with regard to jurisdictional claims in published maps and institutional affiliations. 